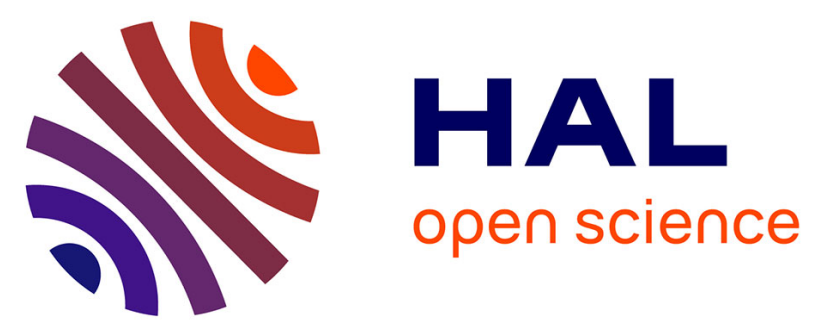

\title{
Automatic derivation of on-demand tactile maps for visually impaired people: first experiments and research agenda
}

Guillaume Touya, Sidonie Christophe, Jean-Marie Favreau, Amine Ben

Rhaiem

\section{To cite this version:}

Guillaume Touya, Sidonie Christophe, Jean-Marie Favreau, Amine Ben Rhaiem. Automatic derivation of on-demand tactile maps for visually impaired people: first experiments and research agenda. International Journal of Cartography, 2019, 5 (1), pp.67-91. 10.1080/23729333.2018.1486784 . hal01980146

\section{HAL Id: hal-01980146 \\ https://hal.uca.fr/hal-01980146}

Submitted on 26 Mar 2019

HAL is a multi-disciplinary open access archive for the deposit and dissemination of scientific research documents, whether they are published or not. The documents may come from teaching and research institutions in France or abroad, or from public or private research centers.
L'archive ouverte pluridisciplinaire HAL, est destinée au dépôt et à la diffusion de documents scientifiques de niveau recherche, publiés ou non, émanant des établissements d'enseignement et de recherche français ou étrangers, des laboratoires publics ou privés. 


\title{
Automatic Derivation of On Demand Tactile MaPs For VISUALLY IMPAIRED PEOPLE: FIRST EXPERIMENTS AND RESEARCH AGENDA
}

\author{
PREPRINT - THE PUBLISHED VERSION CAN BE FOUND HERE: \\ HTTPS://DOI.ORG/10.1080/23729333.2018.1486784
}

\author{
Guillaume Touya \\ LASTIG, COGIT \\ Univ. Paris-Est, IGN, ENSG \\ F-94160 Saint-Mande, France \\ guillaume.touya@ign.fr
}

\author{
Sidonie Christophe \\ LASTIG, COGIT \\ Univ. Paris-Est, IGN, ENSG \\ F-94160 Saint-Mande, France \\ sidonie.christophe@ign.fr \\ Amine Ben Rhaiem \\ LASTIG, COGIT \\ Univ. Paris-Est, IGN, ENSG \\ F-94160 Saint-Mande, France
}

\author{
Jean-Marie Favreau \\ LIMOS \\ Université Clermont Auvergne \\ F-63178 Aubiere, France \\ j-marie.favreau@uca.fr
}

March 26, 2019

\begin{abstract}
Tactile maps are essential tools for visually impaired people to comprehend space and to support the simple pedestrian trips made difficult by their disability. Tactile maps are created manually and printed by specialists, and it takes a large amount of time to create a new one, which prevents using them on demand for everyday use. As a consequence, researchers and cartographers try to automate this creation process, but the existing automated derivation processes do not include generalization or advanced stylization steps, which limits their effectiveness. This paper reports first experiments to include such complex automated cartography processes to provide on demand tactile maps for visually impaired people. These first experiments were more intended to raise real research issues than solve them, and the paper discusses these issues in a research agenda to achieve automatically derived tactile maps.
\end{abstract}

Keywords cartography · tactile map · visual impairment · map generalization · stylization $\cdot 3 \mathrm{D}$ printing $\cdot$ scale $\cdot$ cognition

\section{Introduction}

People use maps more and more to help them in their daily tasks, whether the map is printed on paper, or displayed on a screen. But visually impaired people do not have access to this help, which penalized them even more to prepare their outdoor trips. They also need maps to learn how to navigate outdoor, what the usual obstacles are. Tactile maps are essential tools to compensate this lack and to provide them a mental representation of space through touch. Several techniques are used to create such tactile maps: relief embossing [1, 2], tactile screens that are often coupled with audio assistance devices [3, 4, 5], and emerging 3D printing techniques [6]. Whatever is the technique used, tactile maps are complex to design for the transcribers, i.e. the people in charge of the creation of such maps [7]. To make this problem even more complex, the ability of visually impaired people to understand tactile maps depends on many factors such as the severity of impairment, or how long they lived with regular sight before being impaired [7], amongst other factors: a map that works for one blind person might not work for the majority of visually impaired people. As a consequence, there is a real need for an adapted automation of tactile map design, fitting the user needs, what we call on demand tactile maps. 
[8] define on demand mapping as the automatic derivation of maps tailored according to specific user requirements. Even with classical two dimensional maps, on demand mapping is a real challenge for researchers in cartography, and changing the final output to a tactile map does not make it easier. Researchers try to provide such on demand maps, and some projects already provide some nice tactile outputs, using for instance the crowdsourced OpenStreetMap dataset [2], [1]. These on demand services all use geographic datasets that were collected to make regular maps, and contain far too much information. As a consequence, the maps provided to be printed as tactile maps are too complex to be as effective as the maps manually crafted by the transcribers or orientation instructors. In these made by-hand maps, only the essential information remain after simplification and schematization. Several types of users need on demand tactile maps [7]. Visually impaired people that will be the end users. The initial exploration of such maps is often made together with orientation and mobility instructors. These map users do have specific requirements that are considered by the map transcribers to design maps. To help these users, we definitely need an adaptive pipeline that collects and integrates the required information, generalize it to the appropriate level of detail, schematize it and stylize it in accordance with haptic perception. We believe that this automatic pipeline can be adapted from similar pipelines developed in existing research for automated cartography [9]. Although audio-tactile interactive devices have been developed by several researches [3, 5, 4], we only focus on printed tactile maps for the sake of simplicity. However, we expect that the main components of an on demand tactile mapping process will be also usable for audio-tactile interactive devices. More precisely, this paper does not propose a model or framework to automatically derive tactile maps, but it describes first experiments to identify the main research issues of automatic on demand tactile maps derivation for cartographers: does the state-of-the-art in automated cartography (map generalization, schematization, advanced stylization, text placement) allows the automatic derivation of on demand tactile maps?

The next section of the paper describes related work on on demand tactile mapping and on guidelines to design effective tactile maps. The third section reports our experiments to design a tactile map of a walking route. The fourth section deals with the assessment of the maps produced during the experiments. The fifth section discusses a research agenda for automated cartography, derived for the experiment results. Finally, the sixth section draws some conclusions and presents future research.

\section{Related Work}

\subsection{On Demand Mapping for Visually Impaired People}

The usual first step of map design is to understand the needs of the map users. In this specific case, there are two types of users for on demand tactile maps: the transcribers or mobility instructors that usually create tactile maps (and teach to visually impaired people how to use them) and that could benefit from automated processes [7], and of course the visually impaired people that use the map to navigate into and to understand the geographic space. Each visually impaired person has specific needs for a tactile map [7], which urges the need for on demand mapping. Some transcribers even separate the map in two or three different map objects to provide the entire required information (e.g. roads and POIs in one, relief in the other) [7]. Therefore, increasing the automation and reducing the time spent on map design would be greatly helpful. When transcribers and mobility instructors are interviewed, spacing is clearly ranked as one of the main variables for tactile map design [10], which also pleads for using more automated cartography. With interactive interfaces widering multi-modal interfaces [11], automated processing will be mandatory, such as multi-scale web mapping is accelerating the need for automated topographic cartography. Finally, as many printing methods exist, it is necessary to know if visually impaired people prefer some of the techniques over others. Past experiments showed that rough paper and microcapsule paper are preferred among classical techniques (others are braillon, smooth paper, rough plastic, smooth plastic, and aluminium), and also perform better on search tasks [12]. The preference is based on the feeling that it was easier to move their fingers across the object in relief.

Related work contains several attempts to automatically create tactile maps from geographical datasets. First, the Talking TMAP ${ }^{1}$ project was an extension of the existing TMAP framework [13], enriched with Talking Tactile Tablets [14]. In this case, only streets with Braille labels and the related audio information are put in the map. Street names are generated around the street map, in line with the streets, but not on the map, to avoid symbol congestion. Then, the TMACS 2 project is the first to use OpenStreetMap (OSM) as a data source for on demand tactile mapping [2]. Maps are generated to be printed by embossing on microcapsule paper. The input of the service is an address or a POI, and then the user adjusts scale and center (all OSM zoom levels available). There is no building in the map to reduce complexity, but the road/path density remains too high in our opinion. The Mapy.cz project follows the same principles as TMACS by generating maps from OpenStreetMap [1]. There are three fixed scales available, related to standard paper sizes, and the map is supposed to be printed by embossing on microcapsule paper. The project only covers Czech Republic,

\footnotetext{
${ }^{1}$ Tactile Map Automated Production

${ }^{2}$ Tactile Map Automated Creation System
} 
but more map features are handled compared to TMACS (including buildings), and so maps are too complex for the users. On a more limited geographic extent (city of Brno, Czech Republic), an automated system based on ArcGIS software has been developed [15]. The input geographic data comes from the Czech national mapping agency, and some minimal generalization is performed, which requires some manual post-editing. This is a promising first step towards automated tactile mapping. There is also a service specifically dedicated to mobility instructors [16], while the others target both instructors and visually impaired users.

With the development of 3D printing, researchers try to use this technology to go further from usual embossing. For instance, an additive printing technique, based on glued layers of gypsum powder has been used to create 3D maps representing hypsometry with colors for teaching geography to visual impaired children and adults [6]. A similar technology has been used to print a 3D model derived from airborne LIDAR and orthophotos [17].

Despite their proved effectiveness for visually impaired people printed tactile maps suffer the same defect as paper maps versus web maps: the lack of interactivity. So researchers proposed the use of tactile screen augmented with audio information to replace or complement tactile maps. As only touch is available to interact with the screen, the panel of touch interactions with the map has to be extended by visually impaired people. For instance, [18] propose a prototype with multi-touch (10 parallel touch inputs handled, one per finger). Others use audio as a guidance to understand spatial relations, particularly the complex structures that are abstracted as simple polygons in tactile maps, but also qualitative relations such as "passing by" a landmark [19]. Given the finger movement, the system decides if the user is exploring a track, a landmark, or a region and gives the appropriate verbal assistance. Researchers focused on the types of possible interactions in a navigation task: [20] propose to fix the location of the start and the end of the route (e.g. start at the middle left, end at the middle right) and this proposal clearly improves the results in their user survey. GeoTablet [4] uses sound and vibration interactions on a tactile smartphone screen. Toponyms are announced when the related geographic feature is touched on the map. Environmental sound (e.g. tide sounds when touching the sea) and vibrations when inside an area, are generated by the system.

But it is not easy for visually impaired people to know where to touch the tactile screen in order to get audio information, so researchers have recently started mixing the advantages of both techniques (printed tactile map and audio-tactile screen) with "tangible maps" that are tactile screens with a 3D map on top of the screen [5]. Devices were first developed with a line-raised paper map printed on top of a tactile multi-touch screen [3]. A user survey showed a very good response from blind people against the same map with Braille and no audio. Some tangible objects can also be added on top of the screen to enable classical map interactions such as pan and zoom (the tangible objects are displaced when the user pans or zooms) [5]. LucentMaps is a device with transluscent 3D printed map put on top of a tablet to enable audio-augmented exploration of the part [21].

From the analysis of this related work, we can conclude that:

- creating on demand tactile maps, built automatically from geographical datasets, is necessary, and several researchers are already trying to achieve this goal;

- audio-tactile devices based on tactile screens are gaining much interest due to the possible interactions with the map;

- there is no use yet of advanced automated cartography (generalization, schematization, text placement, stylization), except the generalization operations used by [15].

\subsection{Guidelines for Understandable Tactile Maps}

Cartographers have studied how the human eye perception constrains map design [22]. For instance, there should be at least $0.1 \mathrm{~mm}$ on a paper map between two symbols to be discriminated. These limitations do not apply to tactile maps but similar studies have been carried out on the haptic perception limits [23, 24, 25, 26, 27]. For instance, Bertin variables for map semiology can be adapted to tactile maps [26], and they are all still valid (except color for totally blind people), and the elevation of the tactile map is added as a new variable.

Automated cartography is usually monitored by constraints that translate the eye perception limits and user needs [28]. We tried to synthesize the past research on the haptic perception limits to define such constraints for tactile maps. Table 1 shows an extract of these constraints.

Sets of punctual symbols that are easily understandable through touch have also been proposed and tested with visually impaired people [24, 2, 1]. There is even a proposal for standardization of tactile map symbols [30].

Regarding text, there are guidelines for inserting Braille into tactile maps [29]. One of the main constraints in inserting Braille characters in map is to use very small words. Given the common length of text in maps (e.g. the famous street name "Avenue des Champs-Elysées" in Paris), abbreviations are required to keep the text short. 
PREPRINT - MARCH 26, 2019

Table 1: An extract of the specifications for tactile maps synthesized from the literature on tactile mapping.

\begin{tabular}{|c|c|c|c|c|}
\hline Constraint & Geometry type & Property & Condition & Reference \\
\hline $\begin{array}{l}\text { Minimum height } \\
\text { difference }\end{array}$ & all & height & $\begin{array}{c}\text { height } \\
\text { differences }>0.5 \\
\mathrm{~mm}\end{array}$ & [27] \\
\hline $\begin{array}{l}\text { Line maximum } \\
\text { granularity }\end{array}$ & line and polygon & granularity & $\begin{array}{c}\text { edge length }>8 \\
\mathrm{~mm}\end{array}$ & [27] \\
\hline $\begin{array}{l}\text { Point symbol } \\
\text { minimum } \\
\text { diameter }\end{array}$ & point & diameter & $\begin{array}{c}\text { diameter } \\
\mathrm{mm}\end{array}$ & [15] \\
\hline $\begin{array}{l}\text { Minimum line } \\
\text { width }\end{array}$ & line & width & width $>6 \mathrm{~mm}$ & [15] \\
\hline $\begin{array}{l}\text { Space between } \\
\text { two lines }\end{array}$ & line & $\begin{array}{c}\text { separation } \\
\text { between } 2 \text { lines }\end{array}$ & distance $>5 \mathrm{~mm}$ & [25] \\
\hline $\begin{array}{l}\text { Minimum length } \\
\text { of a line }\end{array}$ & line & length & $\begin{array}{c}\text { length }>12.5 \\
\mathrm{~mm}\end{array}$ & [25] \\
\hline $\begin{array}{c}\text { Minimum area of } \\
\text { polygons }\end{array}$ & polygon & area & area $>6 \mathrm{~mm}^{2}$ & {$[15$} \\
\hline $\begin{array}{l}\text { Space between } \\
\text { two polygons }\end{array}$ & polygon & $\begin{array}{l}\text { separation } \\
\text { between } 2 \\
\text { polygons }\end{array}$ & $\begin{array}{c}\text { distance }>=13 \\
\mathrm{~mm}\end{array}$ & [27] \\
\hline $\begin{array}{l}\text { Minimum size of } \\
\text { Braille cells }\end{array}$ & text & size of Braille cell & size $=7 \mathrm{~mm}$ & [29] \\
\hline
\end{tabular}

Scale is also a major factor for map design, as it constrains the abstraction level used to represent geographic features in the map [31]. Due to the space required around map symbols in the tactile maps, areas with dense information require a larger scale, and maps with varying scales, such as the ones discussed by Godfrey [32], may be convenient to deal with spaces with varying information density. In fact, previous studies even concluded that tactile maps with varying scales are better understood by visually impaired people than maps with a fixed scale [33]. Finally, we found no evidence on the optimum size of a tactile map. However, the visually impaired participants of a survey on where the map should be used (at home, in situ...) commented that due to their weight, tactile maps should not be portable [10]. So the fact that the map is portable or not should not be a factor for determining the best size for a tactile map.

\section{Experiment to Derive a Tactile Map from Geographical Information}

We believe that using the advanced cartographic techniques developed for classical paper or web maps could greatly improve the process to derive tactile maps from geographic data. In order to better understand the research issues related to the application of automated cartography to tactile mapping, we decided to test these issues on a simple use case. The goal is to create a map to be printed on a simple 3D printer that could be available at home for the general public in the near future. We first decided to create the tactile map of the use case by manually transforming the geographic data, and then, we tried to use automatic processes to obtain a similar map. This section describes the use case, and the steps of the manual transformation: data collection and enrichment, generalization, schematization, stylization, text placement, and 3D printing.

\subsection{Use Case}

The use case corresponds to one of the main functions of maps, route planning: mapping the route from the nearest metro station to IGN (French National Mapping Agency) entrance (Figure11). This route is a 5-10 minutes walk, and experience shows that it can be complex for visually impaired people with several roads to cross.

The goal is to derive a simple map as a gray-scale image where gray-scale stands for the height of printing. Gray-scale images are standard inputs for most 3D printers including the one used in this experiment (see Section 3.7). The manual transformations was carried out using the QGIS and Adobe Illustrator. 


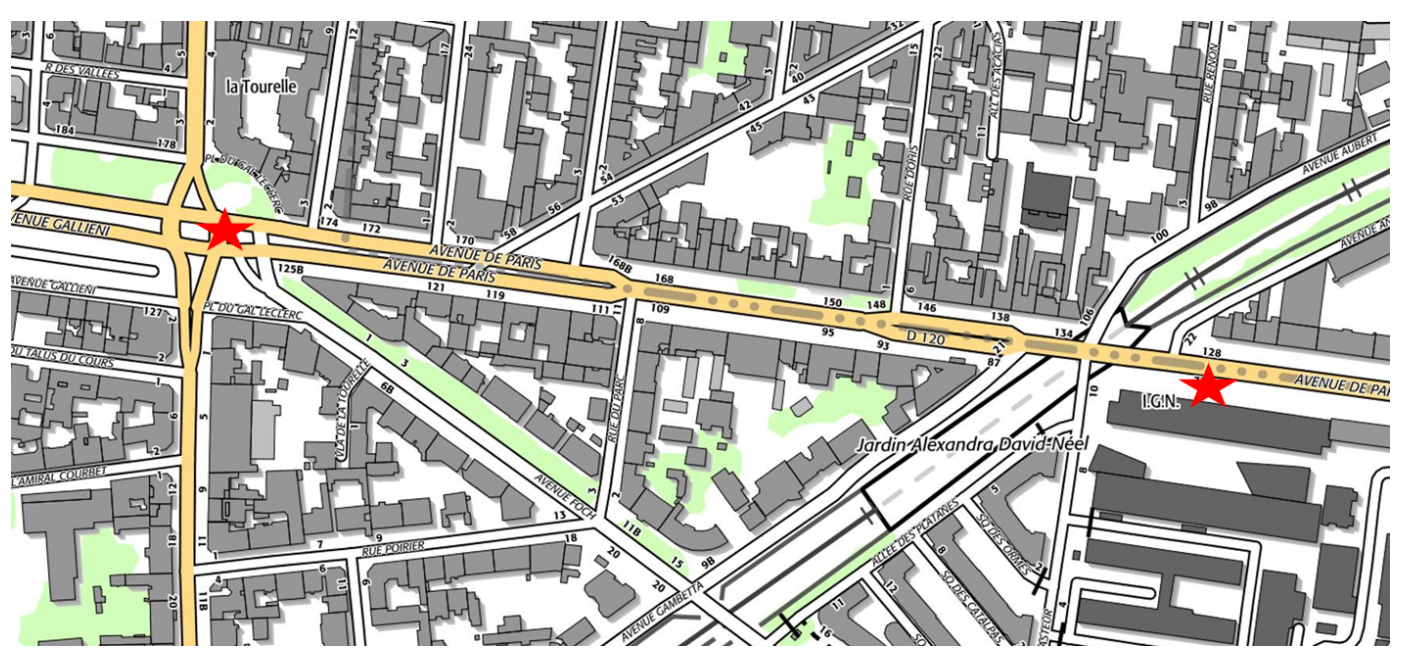

Figure 1: Use case shown on IGN 1:25000 map: mapping the route from the metro station to IGN entrance.

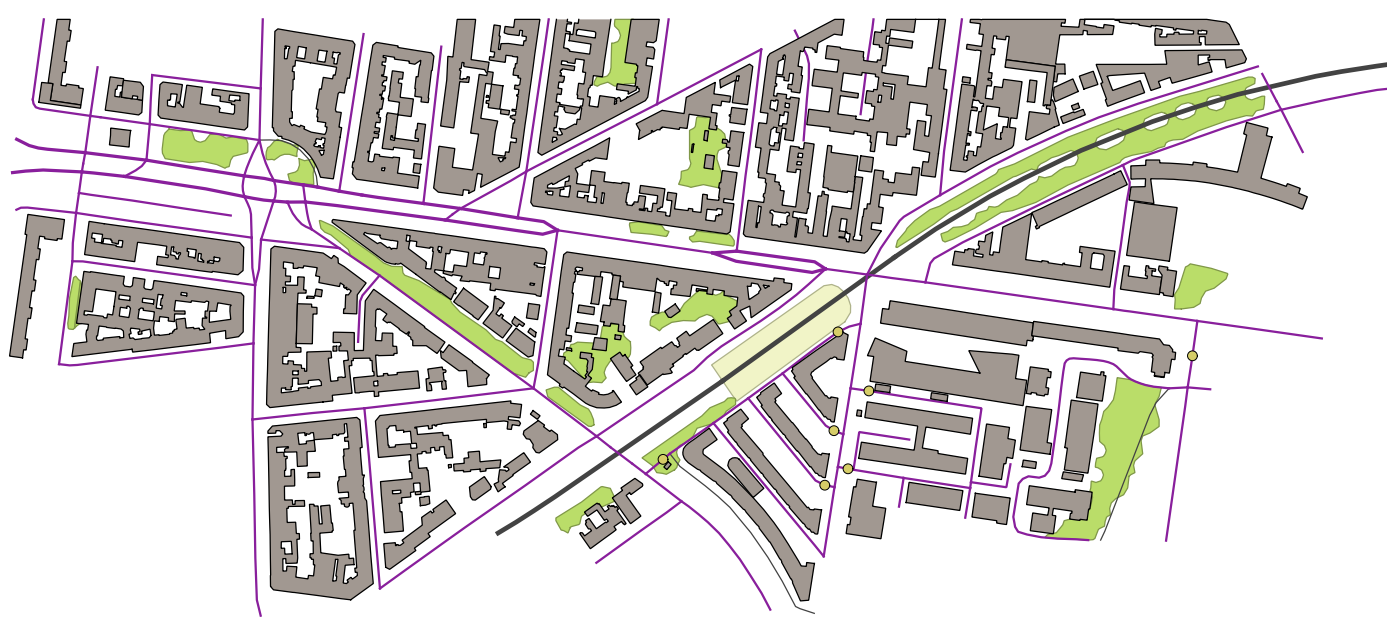

Figure 2: Initial data extracted from IGN (the French mapping agency) datasets.

In order to get a good balance between the space for map features and the size of the printed map, we decided to target a 1:2000 scale map (the map is then approximately $30 \mathrm{~cm}$ long and $15 \mathrm{~cm}$ wide).

\subsection{Data Collection and Enrichment}

The first step is to get the appropriate input data, which will potentially involve collecting data from different datasets, but also enriching the collected data with features that are implicit in these datasets.

\subsubsection{Data Collection}

We first collected the topographic data available at IGN (Figure 2) data. This initial dataset contains detailed buildings, road lines, vegetation and park areas, and barriers as points. However, some important features for routing lack in this dataset: zebra crossings and traffic lights. In this case, they were manually extracted from aerial photographs, but they could also be extracted from OpenStreetMap that contains this information in large European cities.

\subsubsection{Data Enrichment}

Data enrichment is the process that analyze a geographic dataset to identify implicit structures, complex features, or spatial relations, and make them explicit object of the dataset. This step is essential in map generalization as making the enriched features explicit enables their preservation or simplification during the generalization process [34]. 


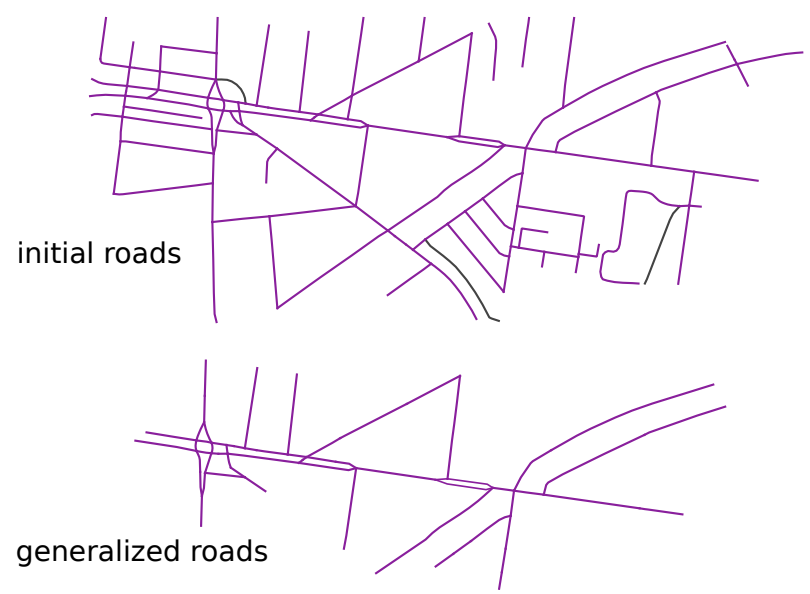

Figure 3: Initial data extracted from IGN (the French mapping agency) datasets.

In our use case, we identified roundabouts that are complex crossroads for visually impaired people, using the method from [35]. Interviews of visually impaired highlighted that they were sensible to empty spaces around them, and they were identified as in [36] to better preserve them.

People with normal vision understand the geography depicted by maps mostly because they are able understand the spatial relations between the map features. But this is much more difficult for visually impaired people that only rely on haptic perception. That is why it might be necessary to make the important spatial relations explicit in the map with specific symbols. In our case, we decided to extract the locations of crossroads to make them explicit in the map with a point symbol. Interestingly, this necessity to make spatial relations explicit matches practices in map generalization where the important spatial relations are made explicit to preserve them [37]. In this experiment, the spatial relation detection was limited to crossroads (that will be depicted by symbols), and to tree-lined streets, in order to preserve the position of vegetation patches along a street.

\subsection{Generalization}

After the collection of the input data and its enrichment to enable the map derivation process (manual in this experiment), the input has to be generalized. The following generalization process was manually carried out:

1. road and building selection

2. building simplification and squaring

3. roads and railways simplification

4. vegetation patches smoothing

5. contextual displacement of buildings and vegetation patches

Road selection is a classical map generalization operation that consists in retaining the most prominent roads in a network while preserving the connectivity and the structures of the network [35]. In this case, the main factor for prominence was the visibility of the roads from the route, and given the scale, all the roads that are connected to the route are retained in the map and all others are removed (Figure 3 .

The same principle was applied to building selection by removing the buildings that are not visible from the route path. Buildings are considered as not visible if they are too far from the route or if they are behind another building.

Then, to reduce the granularity of buildings, they have been significantly simplified and squared [38]. (Figure 4 ) shows how a group of buildings has been simplified and squared in the experiment. Although the simplification level is high, we believe that it is still a building simplification rather than a schematization [39], and that it can be obtained by automated algorithms dedicated to building simplification, just by exaggerating the parameters. This assumption is strengthened by the results of the automatic experiment presented in Section 4.

Vegetation patches are merged then when close to each other, and either smoothed when their geometry is initially curvy, and simplified when the geometry is initially square (Figure 5). 


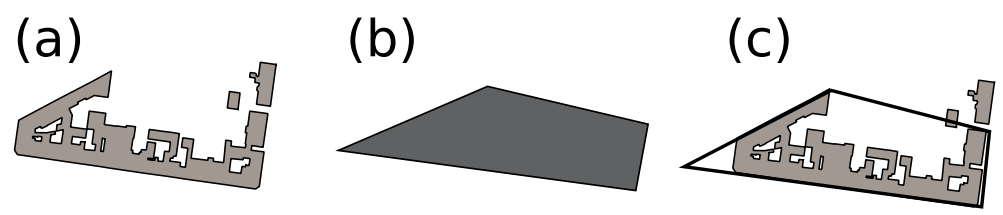

Figure 4: Building generalization: (a) initial buildings; (b) generalized building; (c) initial and generalized buildings superimposed.
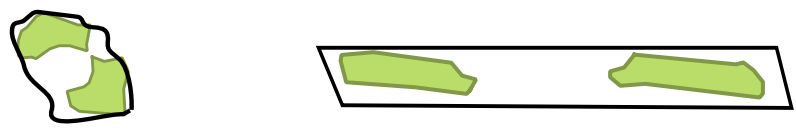

Figure 5: Vegetation patches generalization: initial patches in green and generalized ones with a gray outline.

Finally, the last step of the generalization process applied in our experiment is a contextual displacement [40] of the buildings and vegetation patches to follow the guidelines regarding the separation between two symbols. The roads were not displaced at this stage, but were at the schematization stage described in the following subsection.

\subsection{Schematization}

Different schematization steps are performed to obtain a more abstract map:

- First, it appears that the generalization process was not enough to free some space around the start and the end of the route, where more information is necessary in the map. To tackle this problem, it was decided to use varying scale schematization (Figure 6), as suggested by [33], which showed that it was more effective to display the areas with dense information (around the optimal route), and the contextual areas. The schematization we used can be compared to the focus + context visualization technique where the focus is put on the route [41]. A similar approach was also proposed by godfrey 17 in the context of multi-modal (e.g. walk, then bus, then metro) route maps. The scale used in the magnified areas is approximately 1:1000.

- Then, we observed on the existing tactile maps designed by transcribers that road and railway networks are often schematized with straight lines, in order to look like metro maps [42]. So, we use the same principle by constraining the roads to three orientations: $0^{\circ}, 45^{\circ}$, and $90^{\circ}$. But, to better preserve the shape of the blocks delimited by turning roads, we relaxed a little bit these constraints by allowing $45^{\circ}$ roads to have slight parts that are not $45^{\circ}$ (Figure 6).

- As part of the metro map-like schematization, we followed the suggestion from paladugu10 to put the start of the route on the middle left of the map, and the end of the route on the middle right: all the map features were rotated by approximately $10^{\circ}$.

- A last schematization operation was carried out on roads for the sake of zebra crossing representation: we decided to clearly separate the road lanes of the main roads, even when there was no separation of the lanes on the ground. This last operation is not backed up by any user experiment, so we are not sure it can be understood by a visually impaired user. Otherwise, another solution to clearly represent zebra crossings should be found.

Figure 6 shows the results of the complete road schematization in our experiment. Of course, the other map features were displaced to follow the distortions of the roads.

\subsection{Text Placement}

Braille cells need more space than Roman characters to be rendered, and the street names to put in the map can sometimes be long, so we decided to use of abbreviations which is quite usual in tactile maps [29]. Given its importance in the route depicted by our tactile map, the name of the main road to follow IGN is placed between the lines representing the two lanes, and is repeated after each intersection (Figure 7). The other street names are put around the map at the extremities of the road lines, which enables a sequential parsing of the roads to cross to reach IGN (Figure 7).

\subsection{Stylization}

The final step of map design is the stylization of the map features (Figure 8). Two widths are used to distinguish the most important roads (that are depicted by plain lines in relief). Three point symbols have been used for subway exits 

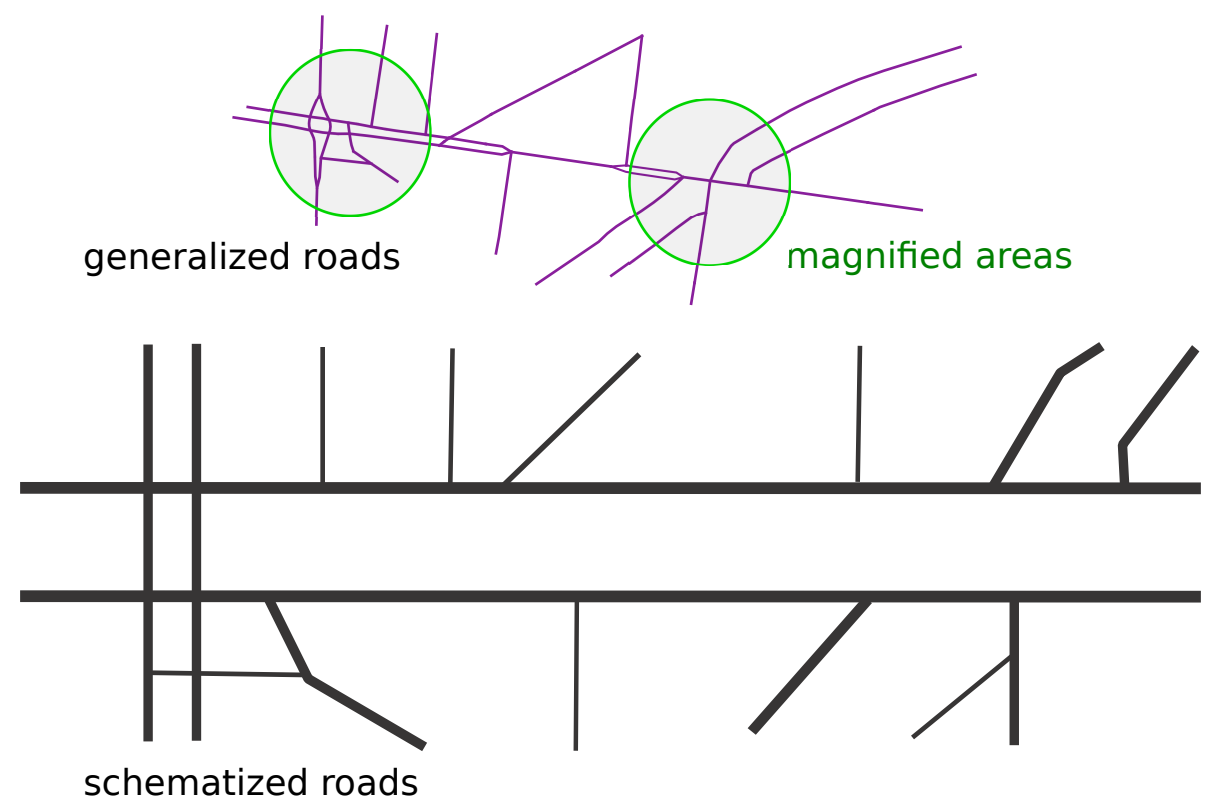

Figure 6: Schematization of the generalized roads: route start and end are magnified, roads are shifted to $0^{\circ}$ (or $90^{\circ}$ or $45^{\circ}$ ), and road lanes are completely separated.

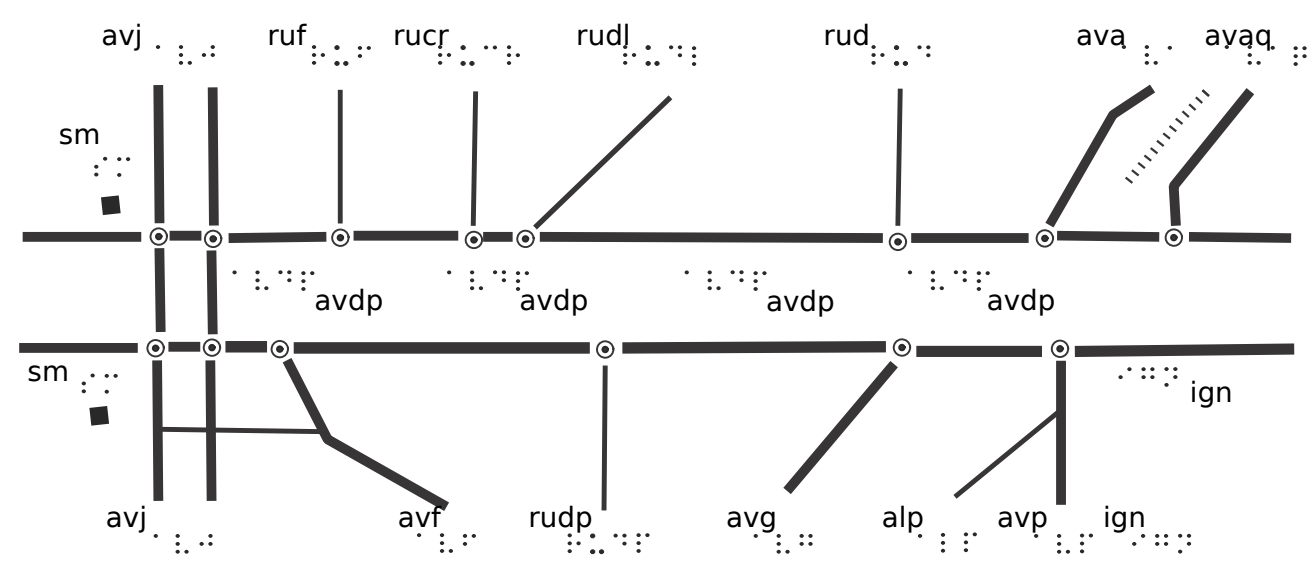

Figure 7: Placement of the Braille text, and the translation in Roman characters. 


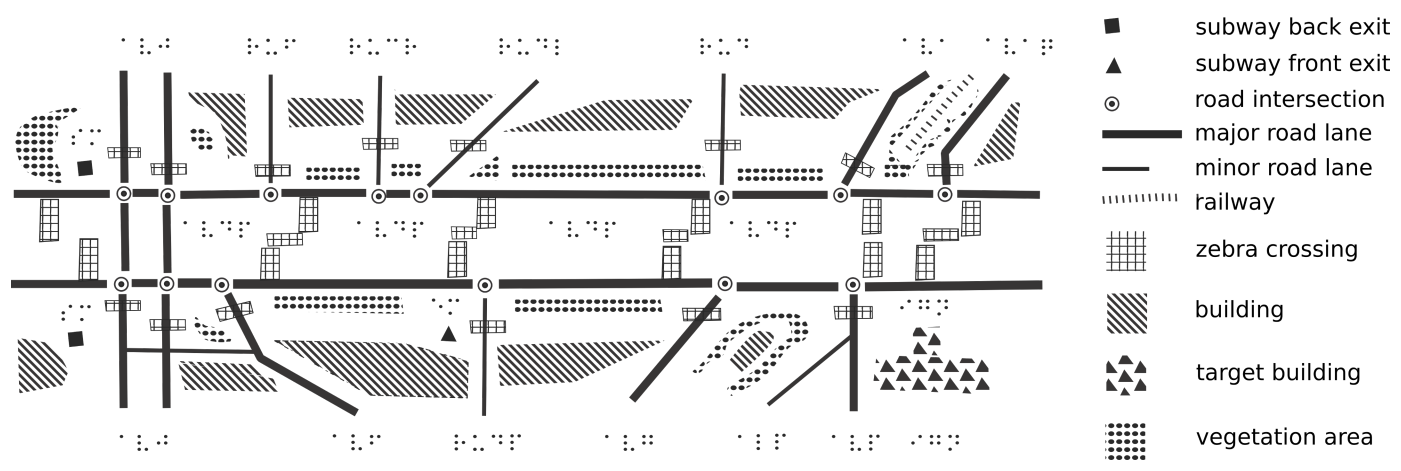

Figure 8: Final output before the printing of our route map with manual schematization, generalization and stylization.

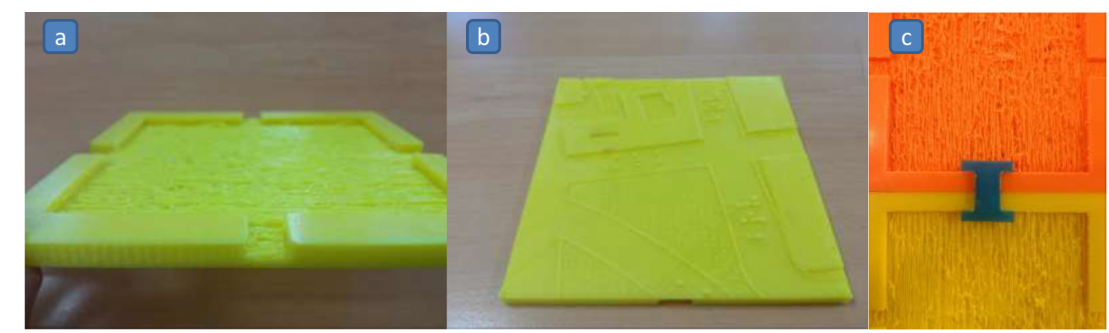

Figure 9: (b) Photograph of a printed map with (a) the hollow verso of the map to allow the clipping of several parts of the map. (c) two printed maps clipped together with a blue clipping device also 3D printed.

and crossroads, following the guidelines of the literature. The railway is represented with a dashed line. And the areal features of the map are represented with textured polygons (zebra crossings, buildings, vegetation patches, and IGN building).

Among the tactile map design variables, textures are particularly important and the ones chosen here follow the results of the studies from nolanMorris71. The design of the texture was performed carefully to avoid texture elements being cut, and thus being too small to be readable by touch, at polygon borders. However, this problems still occurs and this is a challenge for future research (see Section 6.5).

We defined a gray-scale style to be used in a 3D printer, which is to similar to the outputs of existing on demand system, e.g. [2] or [1]. The gray level in the output image encodes the height in the printed map. Four different heights are used:

1. railways and vegetation patches,

2. roads,

3. buildings,

4. point symbols.

\subsection{D Model Generation and 3D Printing}

As the aim is to print the map with a simple non-professional printer in order to simulate further on-demand applications, this type of device requires the generation of a 3D model from the map image. This subsection describes how the 3D model was generated and how it was printed.

The map was modeled in 3D using a triangulation mesh in the open OBJ format 3 each pixel of the map image is given a height, and the mesh is generated taking into account where to insert vertical triangles. As the chosen type of 3D printer is often limited in the size of the objects that can be created, it was decided to cut the map in small pieces that are printed separately and that can be clipped together, using a small device (also 3D printed). To enable this clipping system, we propose to augment the 3D model to include a hollow back of the map (left side of Figure 9), with small gaps in the middle of each edge to insert the small device that clips two parts of the map (Figure 96).

\footnotetext{
${ }^{3}$ http://www.cs.utah.edu/boulos/cs3505/obj_spec.pdf
} 


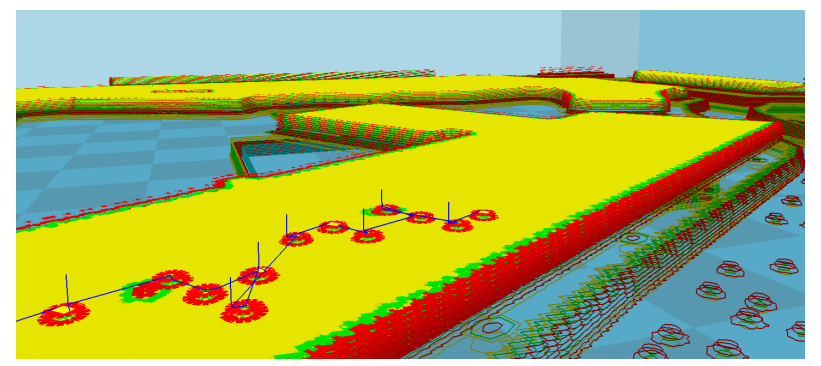

Figure 10: Due to the aliasing on curved shapes, 3D printers are not able to handle properly meshes generated from gray-scale bitmaps. In red: regions with significant small variations which will result in jerking movements of the printer head.

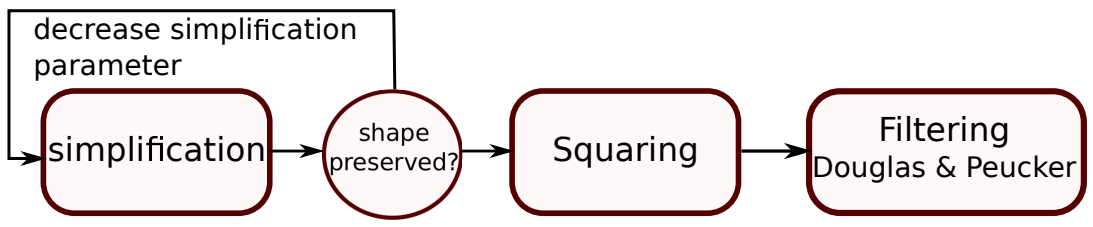

Figure 11: Process used for automatic building generalization.

The printing experiments were not very conclusive, producing relief features that are not smooth enough, and even sometimes very fragile. The main problem seems to be similar to aliasing, when the 3D model is generated from the map image. Figure 10 illustrates the limitation of a bitmap based approach with additive manufacturing. A solution to this problem would be to generate the 3D model from the vector map, rather than using an image, but this idea needs to be experimented (see Section 6).

\section{Derivation with Automatic Processes}

The long term target of this work is to automatically derive on-demand tactile maps: the steps described above should all be automated. As a first experiment, we try to use standard generalization algorithms to automate the generalization steps, i.e. algorithms not adapted to the specific needs of tactile maps. This second experiment shows how far we are from the automation of the generalization process for on-demand tactile maps. This experiment is carried out thanks to the CartAGen research platform [43] that is now available with an open source license ${ }^{4}$ The other processes (text placement, schematization, stylization, and 3D modeling/printing) are not covered by this part of the experiment.

\subsection{Building Generalization}

A quite simple automatic workflow of building generalization is presented in Figure 11. It is slightly iterative because the simplification did not perform well on some very complex buildings. So when the simplification algorithm damages too much the initial shape of a building, the simplification is reverted and a new simplification is carried out with a smaller parameter value until the simplified shape stays close enough to the initial one.

The simplification algorithm is the one included in the AGENT generalization model [44]. The shape preservation checking step is also based on the AGENT generalization model [44], using the same spatial measures: orientation, compactness, convexity, and size. The squaring operation is performed using the least-squares based algorithm from [38]. The final filtering step is necessary to remove the vertices when three or more are aligned after squaring: the Douglas-Peucker algorithm is used with a very small threshold $(0.5 \mathrm{~m})$. Results are presented in Figure 12 .

\subsection{Road Generalization}

The first step of road generalization is the selection of the roads that should be displayed in the map. In this case, the scale allows the preservation of minor, and the selection is based on the usefulness given the purpose of the map, i.e. only roads visible from the route are selected. To select visible roads, we simply intersected a buffer of the central road

\footnotetext{
${ }^{4}$ https://github.com/IGNF/CartAGen
} 


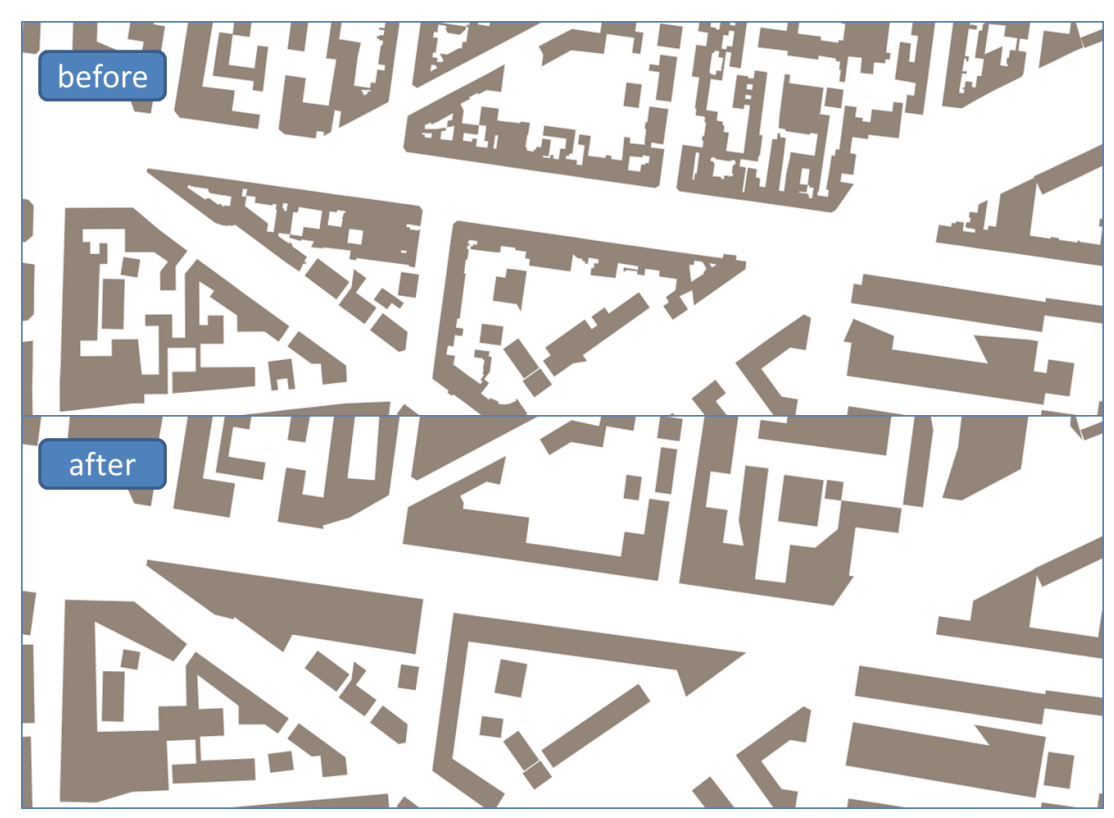

Figure 12: Process used for automatic building generalization.

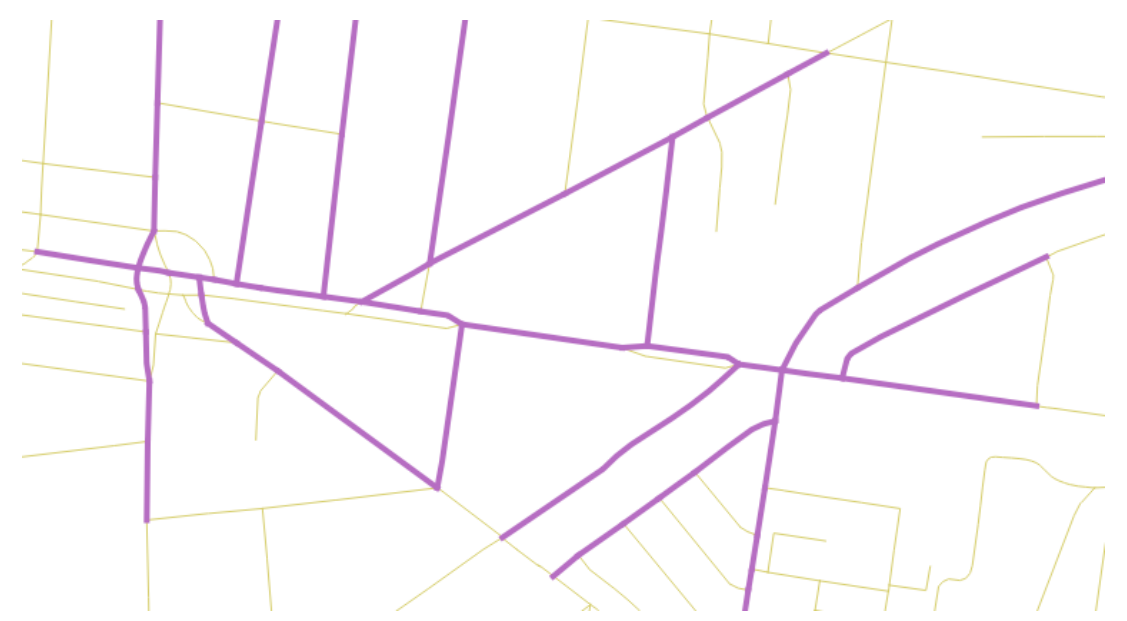

Figure 13: Automatic road selection and complex crossroads collapse.

with the initial roads (Figure 13). In addition to this simple selection, we automatically identified complex crossroads and collapsed them with the methods from [35].

After the selection and collapse steps, the roads are simplified with the Douglas-Peucker algorithm with a high threshold $(50 \mathrm{~m})$, as most roads in the area are quite straight. The results are presented in Figure 14

\subsection{Vegetation Generalization}

Vegetation patches also need to be simplified and sometimes merged to the patches that are too close. So we used a simplification approach based on morphological operators (erosion and dilation), similar to the one proposed by damenEtAl2008 for buildings, because it includes simplification and merge in the same algorithm. Patches are dilated and eroded several times, with different thresholds to obtain the results presented in Figure 15.

\subsection{Inter-Theme Consistency}

In this experiment, the inter-theme consistency is limited to the possible overlaps between features that are generalized separately, i.e. buildings, vegetation patches and roads. First, vegetation patches and buildings that are not visible 


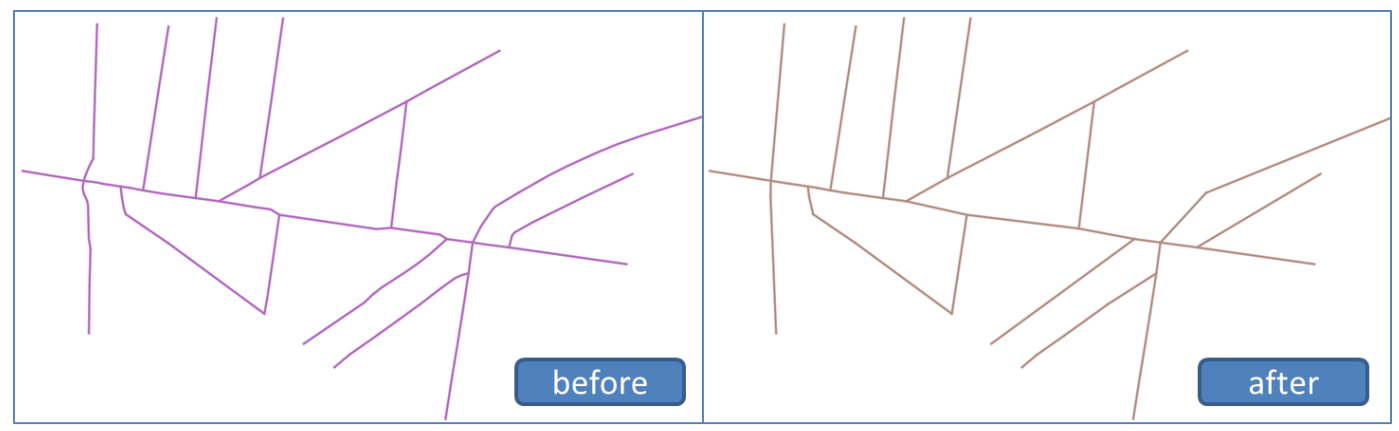

Figure 14: Process used for automatic building generalization.

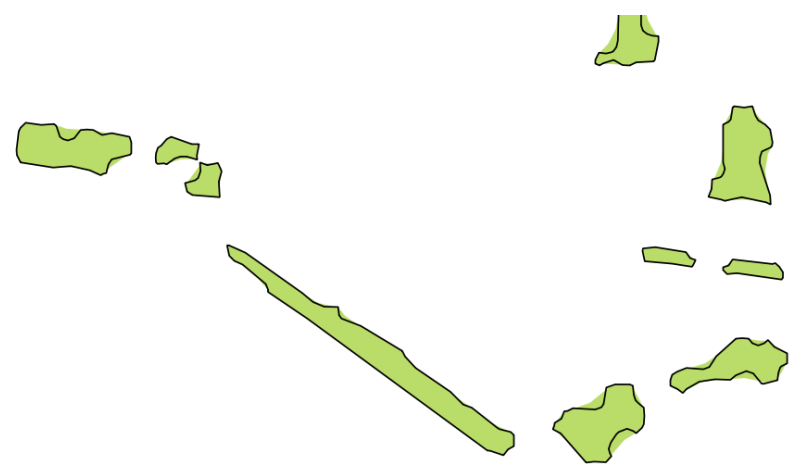

Figure 15: Automatic generalization of vegetation (initial with black lines) using a dilation-erosion principle.

from the route are deleted: if rays traced from the centroid of the features to the central road intersect a building, the features are considered as not visible. Finally, all the features are processed by a displacement algorithm available in the CartAGen platform, which iteratively displaces features; inter-distances are optimized by a gradient descent algorithm. The final results are presented in Figure 16

\section{Assessment of the Maps}

Two types of assessments of the produced maps were conducted, and are presented in this section: a critical evaluation of experts in cartography of the 2D gray-scale map; and a comparison to existing on demand maps.

\subsection{Critical Evaluation}

We presented the map (Figure 8) to several experts of cartography from our research groups, and their comments are reported in this subsection. Obviously, this expert evaluation is not enough, and a user evaluation is required (see the research agenda Section 6.

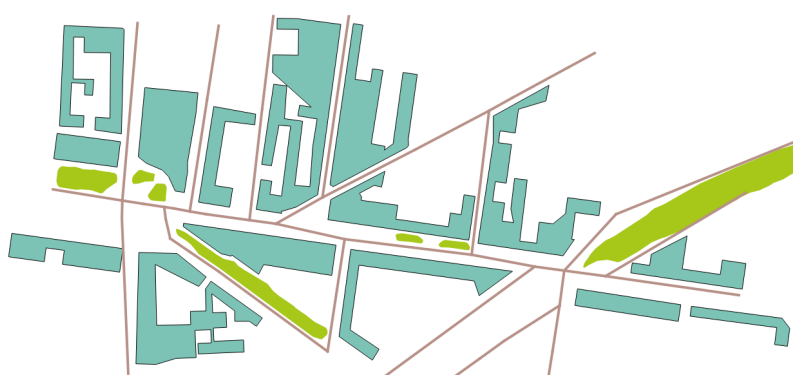

Figure 16: Generalized map after final displacement step. 


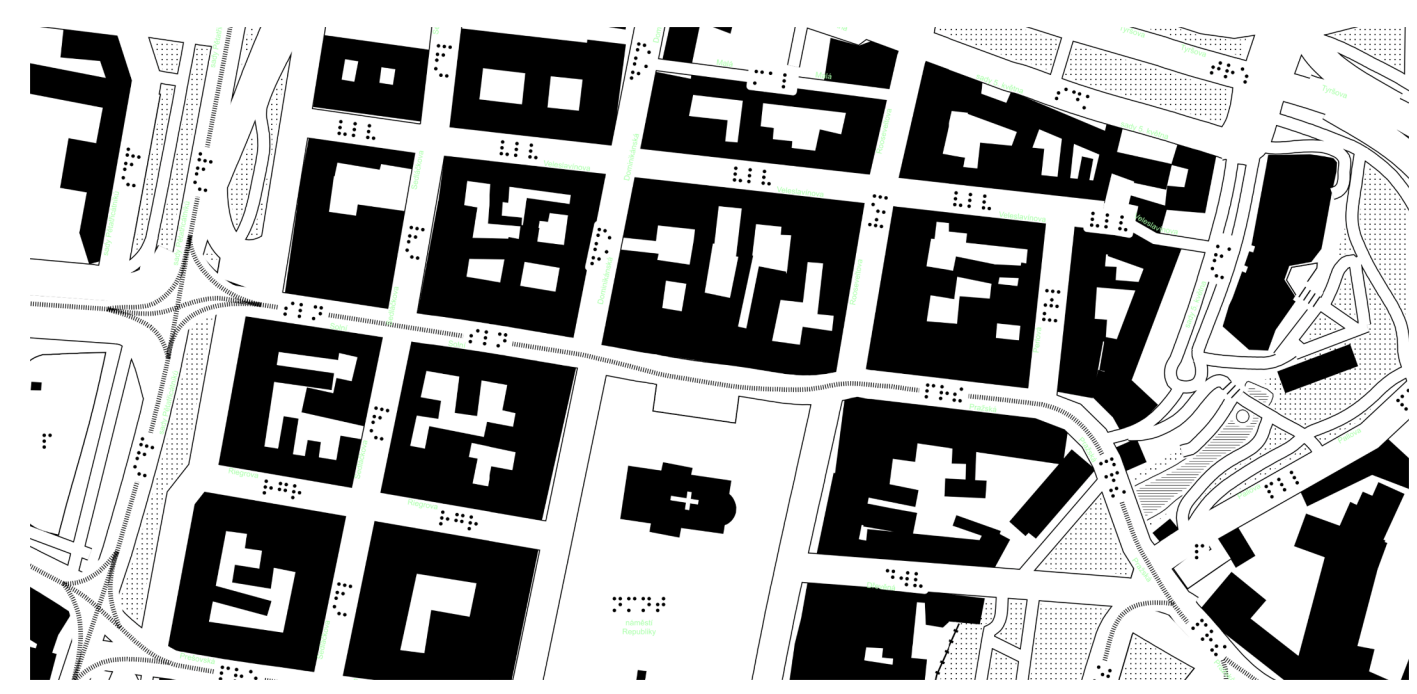

Figure 17: Final output before printing of our route map with manual schematization, generalization and stylization.

- The first blindingly obvious problem is the representation of roads. The proposed approach has to advantages to let free space for Braille and other symbols, but it is very complex to understand that those two lines represent the two lanes of the same road.

- We also believe that the map is still too complex for visually impaired people regarding the amount of information (too many Braille, too many vegetation patches), and the granularity of some polygonal shapes (some angles are too sharp).

- The high level of schematization is well received.

- The textures applied to polygon features lead to artifacts, i.e. only a small part of the texture is sometimes included in the polygon making the small remaining part to small to be understood by touch, which should be avoided (see for instance the IGN building with the triangle-based texture). If a texture element cannot be entirely rendered, it should not be rendered at all, rather than partly rendered.

- Finally, there is a problem with the representation of zebra crossings by textured polygons. A representation with a line would be preferable.

\subsection{Comparison to Existing On Demand Maps}

In order to further assess the manually derived map, or at least its two-dimensional version, we tried a comparison with a map from Mapy.cz on a similar area in both size and geographical content (Figure 17), because it is not possible on the same area as the service is only available on Czech areas.

There are clear differences in the stylization (roads only represented by hollow areas, no use of point symbols), but if we only focus on the generalization/schematization aspects. We note that:

1. road density is very high, and complex crossroads add even more complexity and should be difficult for visually impaired people to understand;

2. railroad complex junctions are also left unmodified;

3. text density is very important in the Czech map;

4. building granularity is very high, all the small courtyards inside building blocks must be very complex for users;

5. many map symbols overlap, which is even more complex to understand in tactile maps than classical maps.

Even if these maps are not primarily meant to be seen, it is interesting to measure their visual complexity to assess their potential tactile complexity. Clutter measures are techniques from the computer vision research domain to assess visual complexity [45], and have been successfully applied to maps in the past [46, 47]. Table 2] shows the results from several clutter measures already used in [46] applied on Figure 8 and Figure 17] Even if each absolute value is complex to analyze, all measures confirm that our map is way less visually complex that the on demand map from Mapy.cz, 
PREPRINT - MARCH 26, 2019

Table 2: Clutter measures of the tactile maps before printing.

\begin{tabular}{lcccc}
\hline \multirow{5}{*}{ Map } & \multicolumn{3}{l}{ Clutter measures } & \\
\cline { 2 - 5 } & edge density & subband entropy & quadtree clutter & segmentation clutter \\
\hline our map & 128 & 1.31 & 0.026 & 652 \\
mapy.cz & 213 & 2.58 & 0.039 & 2388 \\
{$[15]$ map 1 } & 2256 & 4.81 & 0.093 & 1225 \\
{$[15]$ map 2 } & 1403 & 7.34 & 0.143 & 1884 \\
\hline
\end{tabular}

which is normal as our goal was to design a less complex map. This assessment gives us clues for the research agenda presented in the following section.

\section{Research Agenda}

\subsection{Data Collection}

The experiment presented in this paper shows that the information available in the datasets of national mapping agencies, such as IGN in France, is not sufficient, and complementary datasets, coming from open data existing initiatives such as OpenStreetMap, or specific data acquisition for the purpose of on-demand maps for visually impaired people should be used. Information about all possible obstacles in the streets, such as all urban equipment what is the size of those entities, should be available. But route maps could also contain unexpected obstacles, not on the ground, but on the facades (new perspective to integrate) such as specific windows equipments, the absence or presence of facades providing meaningful, and such as sensitive clues for visually impaired people to detect walkability and dangerosity of a path. Finally, meaningful information is perhaps not related to existing entities, but related to the meaning of the comprehension of spatial relations, such as the notion of a crossroad. In a citizen science perspectives, it would be interesting to develop tools and protocols that enable visually impaired people to capture themselves such information.

\subsection{Generalization of Heterogeneous Data}

The automated generalization results of the experiment presented in Section 4 show that there is no urgent need for specific generalization algorithms: adapting the existing ones with different parameters seems enough. So, the first step to achieve automation is to test existing methods to orchestrate the automated application of generalization algorithms [48], as we only tested manually selected algorithms on manually selected map features.

But the previous subsection showed that the use of additional crowdsourced datasets might be necessary. Using such heterogeneous datasets together in automated cartography processes raises many problems that need to be addressed to achieve full automation [49]. For instance, gathering information with heterogeneous levels of detail often leads to inconsistencies that damage map readability. Harmonization processes that transform the geometry of detailed and undetailed features are required [50], as well as generalization processes able to adapt their parameters to the varying level of detail of the input data.

\subsection{D Schematization}

In the existing on demand mapping systems, the tactile map features are generalized or schematized as two-dimensional features that are later extruded into 3D tactile shapes, but it could be more effective to design 3D schematization from the two-dimensional initial features to avoid the problems we encountered during the 3D printing step of our experiment.

More generally, the issue of automatically distorting map features, to obtain maps with magnified regions, also needs to be addressed. The emerging techniques for fish-eye lenses or focus maps [51] could be adapted to distort the map while minimizing the impact of distortion on the shape of map features (i.e. straight shapes should not become curvy due to distortion).

\subsection{Automatic Text Placement}

The rules that guide Braille text in general [29], and Braille text in maps make the existing text placement techniques (see [52] for a recent review) useless. They have to be extended to be improved to enable automatic text placement in tactile maps. Beyond the question of the space around the Braille characters, and the overlaps with the map symbols, which can be considered as additional constraints for optimization based text placement techniques, the optimization 


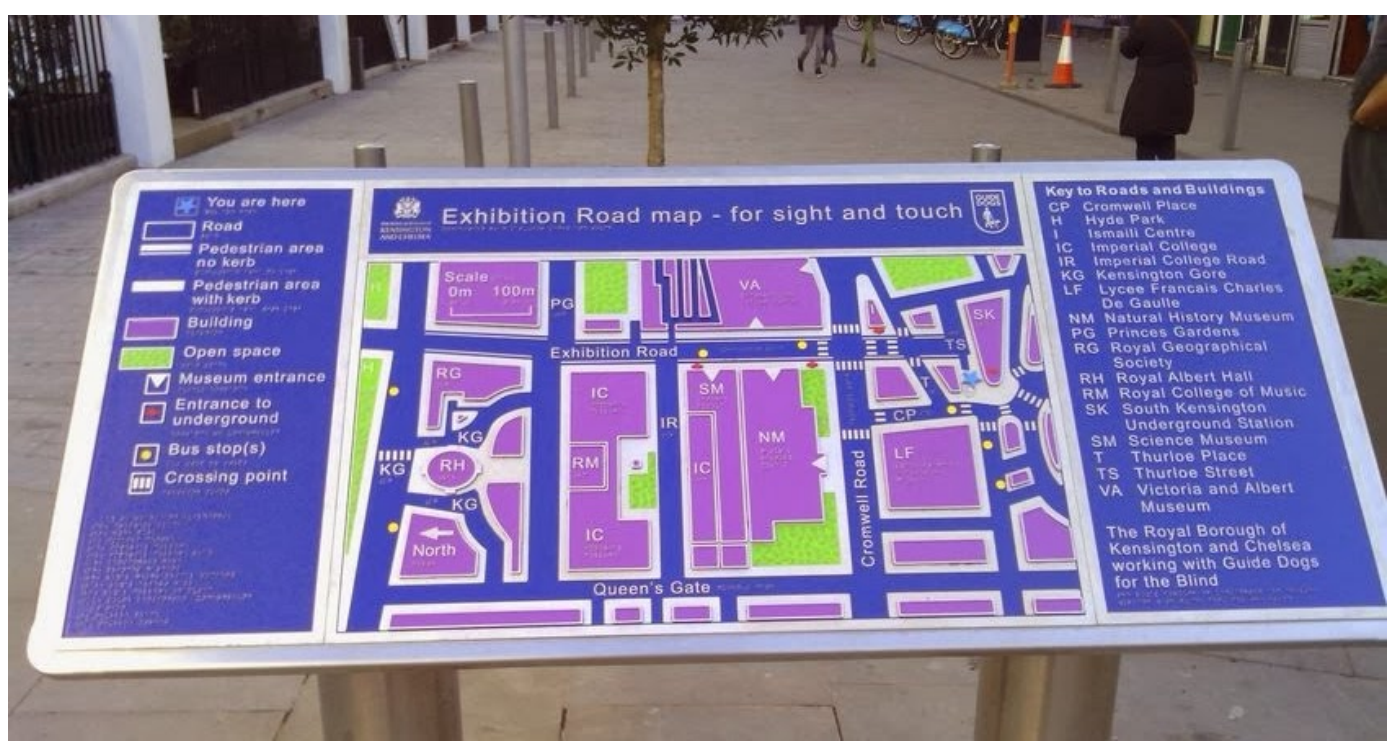

Figure 18: Picture of a tactile map in London where colors also help people visually impaired but not totally blind (C)Jean-Marie Favreau).

of text placement outside or around the map, such as street names in our experiment, requires changes in the way we model the position of text around a map feature: we usually put the text in one of the four or eight possible positions around a feature, which is no longer applicable in the case of tactile maps.

\subsection{Stylization for Tactile Printing}

In order to address the problem of textures rendering at the border of polygons, we believe that research on automatic generation of vector textures [53], yet experimented for printed 3D objects [54], could be adapted for the 3D printing of tactile maps.

Added to that, many of the visually impaired people are not totally blind and do perceive colors and contrasts [55] in some way. So tactile maps can be augmented with colors to help these people understanding the map (Figure 18). The methods that seek to optimize the colors in a map given some constraints, here the limited color perception of visually impaired people balanced with color contrasts [56], could be adapted to augment the map with colors on demand, given the color perception capabilities of the user.

Finally, there are research projects on the specification and optimization of stylization, a way to semi-automatically design and control expressive styles for map design, usable to manage underlying constraints specific to visually impaired people [57, 58]. We believe that such research could be extended to deal with the style of tactile maps, whether they are printed or displayed on audio-tactile devices.

\subsection{Automatic Evaluation}

To verify that the guidelines summarized in Section 2.2 are fully respected, a constraint-based evaluation can be carried out [59]. The goal of automatic evaluation in cartography is to control the iterative process at each step, and to assess where are the remaining problem at the end [60]. The challenge is to extend the principles of constraint-based evaluation that were designed for map generalization to the complete workflow of automatic cartography for tactile maps.

But there is an additional difficulty in the case of tactile maps: a constraint-based auto-evaluation cannot be performed on the printed map, and the flaws due to the printing process would not be evaluated. The same problem occurs for clutter-based evaluation [46] that can only be applied to map images.

\subsection{User Evaluation}

User studies are used more and more in cartography to evaluate the fitness of a map for a specific use [61]. They have been used for many years by researchers interested in cartography for visually impaired people, whether the users are visually impaired or just the transcribers in charge of the design and creation of the maps. So the challenge is not the 


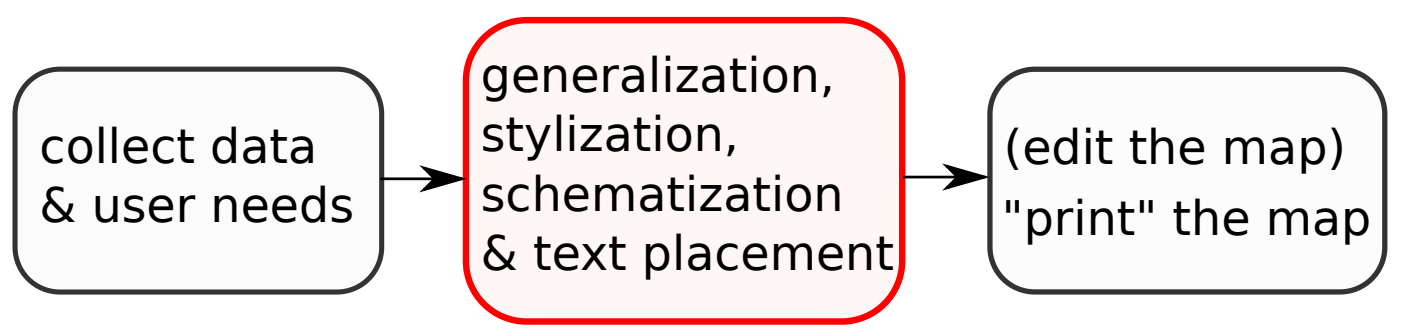

Figure 19: Workflow for on demand tactile mapping: how to orchestrate the central steps?

user experiment itself, but to control the content of the experiment when the variable to assess is a small change in map design.

For instance, if we want to assess the influence only of schematization operations in the on demand tactile mapping process: we will produce maps with scale deformations and other without, and compare both on a navigation task. But whatever the chosen scale for the map without schematization (the large one used in dense areas, or the small one used in sparse areas), the size of the map will be different: it will then be difficult to know if users act more effectively because of the schematization or because of the size of the printed map (maps too small or too large might be harder to handle).

\subsection{Automatic Cartographic Processing for On Demand Tactile Mapping}

Even if all the challenges described above are addressed in the future years, we will still be unable to derive on demand tactile maps, as, even for 2D topographic maps, there was no attempt to design a complete workflow that combines all steps of on demand mapping (Figure 19]. To add even more complexity, an on demand automatic process should be able to deliver simplified maps on demand for several types of users (e.g. several types of visual impairment), several uses (e.g. movement by foot, or car, geographic discovery of a place, etc.), and several printing techniques (e.g. tactile screen with sound, relief embossing, different types of 3D printing). The questions to address are: is there an order to chain the four processes? Is the process iterative? How much each process depends on the results of the others?

\section{Conclusions and Further Work}

All users and practitioners plead for a quicker access to maps for visually impaired people. While some promising on-demand systems now allow a quick on-demand access to maps printable in relief, the lack of automated cartography processes on those systems make the maps hardly usable in practice. This paper reported a first experiment to adapt automated cartography processes (map generalization, schematization, stylization) to this issue of on-demand tactile mapping. The contribution of this paper is the demonstration that using automatic cartography processes is feasible but requires the investigation of several issues, detailed in a research agenda. The experiment also shows that tactile maps are a good use case to test the genericity and the adaptability of the on-demand mapping methods we are working on.

Our future work is to address the main points of this research agenda regarding generalization, schematization, stylization and their inclusion in a global automatic workflow. The evaluation of the maps created by such a system, based on user experiment, is also a big challenge we want to address. Finally, we have seen at the beginning of the paper that even if maps printed in 3D will be useful in many cases, the future of maps for visually impaired people is related to interactive audio-tactile devices. The derivation of interactive multi-scale maps in such systems is major challenge and cartographers will have to team up with computer scientists specialized in human-computer interactions for visually impaired people.

\section{References}

[1] Petr Červenka, Karel Břinda, Michaela Hanousková, Petr Hofman, and Radek Seifert. Blind friendly maps. In Klaus Miesenberger, Christian Bühler, and Petr Penaz, editors, Computers Helping People with Special Needs, volume 9759 of Lecture Notes in Computer Science, pages 131-138. Springer International Publishing, 2016.

[2] Tetsuya Watanabe, Toshimitsu Yamaguchi, Satoko Koda, and Kazunori Minatani. Tactile map automated creation system using openstreetmap. In Proceedings of 14th International Conference on Computers Helping People with Special Needs, Paris, France, July 2014. 
[3] Anke Brock, Philippe Truillet, Bernard Oriola, Delphine Picard, and Christophe Jouffrais. Design and user satisfaction of interactive maps for visually impaired people. In Klaus Miesenberger, Arthur Karshmer, Petr Penaz, and Wolfgang Zagler, editors, Computers Helping People with Special Needs, volume 7383 of Lecture Notes in Computer Science, pages 544-551. Springer Berlin Heidelberg, 2012.

[4] Mathieu Simonnet, Cécile Bothorel, Luiz F. Maximiano, and André Thépaut. Geotablet, une application cartographique pour les personnes déficientes visuelles. In Proceedings of Handicap 2012, volume 7, pages 8-13, Paris, France, June 2012. IFRATH.

[5] J. Ducasse, M. Macé, and C. Jouffrais. From open geographical data to tangible maps: Improving the accessibility of maps for visually impaired people. ISPRS - International Archives of the Photogrammetry, Remote Sensing and Spatial Information Sciences, XL-3/W3:517-523, 2015.

[6] Vit Voženílek, Veronika Růžičková, Dita Finková, Libuše Ludíková, Zuzana Němcová, Jan Doležal, Alena Vondráková, Magdaléna Kozáková, and Vojtěch Regec. Hypsometry in tactile maps. In Manfred Buchroithner, editor, True-3D in Cartography, Lecture Notes in Geoinformation and Cartography, pages 153-168. Springer Berlin Heidelberg, 2012.

[7] Régis Kern. Cartographie et malvoyance - du papier au numérique. Cartes \& Géomatique, 229-230:167-174, December 2016.

[8] Sandrine Balley, Blanca Baella, Sidonie Christophe, Maria Pla, Nicolas Regnauld, and Jantien Stoter. Map specifications and user requirements. In Dirk Burghardt, Cécile Duchêne, and William Mackaness, editors, Abstracting Geographic Information in a Data Rich World, Lecture Notes in Geoinformation and Cartography, pages 17-52. Springer International Publishing, 2014.

[9] Guillaume Touya. Vers l'automatisation de la production de cartes. Habilitation (hdr), Université Paris Est, May 2017.

[10] Jonathan Rowell and Simon Ungar. The world of touch: an international survey of tactile maps. part 2: design. British Journal of Visual Impairment, 21(3):105-110, 2003.

[11] Wolf Günther Koch. State of the art of tactile maps for visually impaired people. In Manfred Buchroithner, editor, True-3D in Cartography, Lecture Notes in Geoinformation and Cartography, pages 137-151. Springer Berlin Heidelberg, 2012.

[12] Simon Ungar, Ra Jehoel, Don Mccallum, and Jonathan Rowell. Tactualization of spatial information: towards a perceptual-cognitive approach to tactile map design. In Proceedings of XXII International Cartographic Conference, La Coruña, Spain, 2005. ICA.

[13] Joshua A. Miele and J. Marston. Tactile map automated production (TMAP): on-demand accessible street maps for blind and visually impaired travelers. In Proceedings of the Annual Meeting of the American Association of Geographers, Denver, CO, USA, 2005.

[14] Joshua A. Miele, Steven Landau, and Deborah Gilden. Talking tmap: Automated generation of audio-tactile maps using smith-kettlewell's tmap software. British Journal of Visual Impairment, 24(2):93-100, May 2006.

[15] Radim Štampach and Eva Mulíčková. Automated generation of tactile maps. Journal of Maps, 12(sup1):532-540, November 2016.

[16] Sabrina Talita de Oliveira, Katsuk Suemitsu, and Maria Lucia Leite Ribeiro Okimoto. Design of a tactile map: An assistive product for the visually impaired. In Francisco Rebelo and Marcelo Soares, editors, Advances in Ergonomics in Design, volume 485 of Advances in Intelligent Systems and Computing, pages 711-719. Springer International Publishing, 2016.

[17] Friederike Schwarzbach, Tapani Sarjakoski, Juha Oksanen, Sarjakoski, and Suvi Weckman. Physical 3d models from lidar data as tactile maps for visually impaired persons. In Manfred Buchroithner, editor, True-3D in Cartography, Lecture Notes in Geoinformation and Cartography, chapter 11, pages 169-183. Springer Berlin Heidelberg, Berlin, Heidelberg, 2012.

[18] Anke Brock, Philippe Truillet, Bernard Oriola, and Christophe Jouffrais. Usage of multimodal maps for blind people: Why and how. In ACM International Conference on Interactive Tabletops and Surfaces, ITS '10, pages 247-248, New York, NY, USA, 2010. ACM.

[19] Christopher Habel, Matthias Kerzel, and Kris Lohmann. Verbal assistance in tactile-map explorations: A case for visual representations and reasoning. In Proceedings of the 7th AAAI Conference on Visual Representations and Reasoning, AAAIWS'10-07, pages 34-41. AAAI Press, 2010.

[20] Devi A. Paladugu, Zheshen Wang, and Baoxin Li. On presenting audio-tactile maps to visually impaired users for getting directions. In CHI '10 Extended Abstracts on Human Factors in Computing Systems, CHI EA '10, pages 3955-3960, New York, NY, USA, 2010. ACM. 
[21] Timo Götzelmann. LucentMaps: 3D printed audiovisual tactile maps for blind and visually impaired people. In Proceedings of the 18th International ACM SIGACCESS Conference on Computers and Accessibility, ASSETS '16, pages 81-90, New York, NY, USA, 2016. ACM.

[22] K. A. Salichtchev. Cartographic communication: A theoretical survey. In D. R. F. Taylor, editor, Graphic Communication and Design in Contemporary Cartography, volume 2, pages 11-36. Wiley, New-York, 1983.

[23] G. Jansson. Rapport nr 44. projektet PUSS XVI: Linjeoch ytsymboler for taktila kartor. Technical report, Uppsala universitet, 1973.

[24] Carson Y. Nolan and June E. Morris. Improvement of tactual symbols for blind children: Final report. Technical report, American Printing House for the Blind, Louisville, KY, USA, 1971.

[25] A. F. Tatham. The design of tactile maps: theoretical and practical considerations. In M. Rybaczac and K. Blakemore, editors, Proceedings of International Cartographic Association Conference: Mapping the Nations, pages 157-166, Bournemouth, UK, 1991.

[26] Regina Vasconcellos. Tactile mapping design and the visually impaired user. In C. H. Wood and C. Peter Keller, editors, Cartographic Design: Theoretical and Practical Perspectives, chapter 8, pages 91-102. Wiley, New York, USA, 1996.

[27] Gem-Ef. Guide de l'acheteur public de produits graphiques en relief à l'usage des personnes déficientes visuelles. Technical report, Observatoire de l'achat public, Ministère des finances, July 2001.

[28] Jantien Stoter, Dirk Burghardt, Cécile Duchêne, Blanca Baella, Nico Bakker, Connie Blok, Maria Pla, Nicolas Regnauld, Guillaume Touya, and Stefan Schmid. Methodology for evaluating automated map generalization in commercial software. Computers, Environment and Urban Systems, 33(5):311-324, September 2009.

[29] Irene Miller, Aquinas Pather, Janet Milbury, Lucia Hasty, Allison O’Day, and Diane Spence. Guidelines and standards for tactile graphics. Technical report, The Braille Authority of North America, 2010.

[30] Amy Lobben. Tactile maps and mapping. Journal of Blindness Innovation and Research, 5(1), 2015.

[31] William A. Mackaness. Understanding geographic space. In William A. Mackaness, A. Ruas, and T. Sarjakoski, editors, The Generalisation of Geographic Information: Models and Applications, chapter 1, pages 1-10. Elsevier, Amsterdam, Netherlands, 2007.

[32] Lucas Godfrey and William Mackaness. The bounds of distortion: truth, meaning and efficacy in digital geographic representation. International Journal of Cartography, pages 1-14, March 2017.

[33] Joseph W. Wiedel and Paul A. Groves. Tactual mapping: Design, reproduction, reading and interpretation. Technical report, US Dept. of Health, Education and Welfare, Washington, DC, USA, 1969.

[34] William A. Mackaness and Geoffrey Edwards. The importance of modelling pattern and structure in automated map generalisation. In Proceedings of the Joint ISPRS/ICA Workshop on Multi-Scale Representations of Spatial Data, pages 7-8, 2002.

[35] Guillaume Touya. A road network selection process based on data enrichment and structure detection. Transactions in GIS, 14(5):595-614, 2010.

[36] Julien Gaffuri and Jenny Trévisan. Role of urban patterns for building generalisation: An application of AGENT. In ICA Workshop on Generalisation and Multiple representation, commission on map generalisation. ICA, August 2004.

[37] Guillaume Touya, Bénédicte Bucher, Gilles Falquet, Kusay Jaara, and Stefan Steiniger. Modelling geographic relationships in automated environments. In Dirk Burghardt, Cécile Duchêne, and William Mackaness, editors, Abstracting Geographic Information in a Data Rich World, chapter 3, pages 53-82. Springer, Berlin Heidelberg, March 2014.

[38] Imran Lokhat and Guillaume Touya. Enhancing building footprints with squaring operations. Journal of Spatial Information Science, 13:33-60, December 2016.

[39] Kevin Buchin, Wouter Meulemans, André Van Renssen, and Bettina Speckmann. Area-Preserving simplification and schematization of polygonal subdivisions. ACM Trans. Spatial Algorithms Syst., 2(1), April 2016.

[40] Yuangang Liu, Qingsheng Guo, Yageng Sun, and Xiaoya Ma. A combined approach to cartographic displacement for buildings based on skeleton and improved elastic beam algorithm. PLOS ONE, 9(12):e113953+, December 2014.

[41] Colin Ware. Information Visualization, Third Edition: Perception for Design (Interactive Technologies). Morgan Kaufmann, 3 edition, June 2012. 
[42] Jonathan M. Stott and Peter Rodgers. Metro map layout using multicriteria optimization. IEEE Transactions on Visualization and Computer Graphics, 17(1):355-362, August 2004.

[43] Jérémy Renard, Julien Gaffuri, Cécile Duchêne, and Guillaume Touya. Automated generalisation results using the agent-based platform CartAGen. In Proceedings of 25th International Cartographic Conference (ICC'11) poster session, Paris, France, 2011. ICA.

[44] Mathieu Barrault, Nicolas Regnauld, Cécile Duchêne, K. Haire, Christophe Baeijs, Yves Demazeau, Paul Hardy, William A. Mackaness, Anne Ruas, and Robert Weibel. Integrating multi-agent, object-oriented, and algorithmic techniques for improved automated map generalisation. In 20th International Cartographic Conference, volume 3, pages 2110-2116. ICA, 2001.

[45] Guillaume Touya, Charlotte Hoarau, and Sidonie Christophe. Clutter and map legibility in automated cartography: A research agenda. Cartographica: The International Journal for Geographic Information and Geovisualization, 51(4):198-207, 2016.

[46] Guillaume Touya, Blandine Decherf, Mayeul Lalanne, and Marion Dumont. Comparing Image-Based methods for assessing visual clutter in generalized maps. ISPRS Annals of the Photogrammetry, Remote Sensing and Spatial Information Sciences, II-3/W5, September 2015.

[47] Arzu Çöltekin, Alžběta Brychtová, Amy L. Griffin, Anthony C. Robinson, Mark Imhof, and Chris Pettit. Perceptual complexity of soil-landscape maps: a user evaluation of color organization in legend designs using eye tracking. International Journal of Digital Earth, 20, October 2016.

[48] Nicolas Regnauld, Guillaume Touya, Nicholas Gould, and Theodor Foerster. Process modelling, web services and geoprocessing. In Dirk Burghardt, Cécile Duchêne, and William Mackaness, editors, Abstracting Geographic Information in a Data Rich World, chapter 7, pages 198-225. Springer, Berlin Heidelberg, March 2014.

[49] Monika Sester, Jamal Jokar Arsanjani, Ralf Klammer, Dirk Burghardt, and Jan-Henrik Haunert. Integrating and generalising volunteered geographic information. In Dirk Burghardt, Cécile Duchêne, and William Mackaness, editors, Abstracting Geographic Information in a Data Rich World, Lecture Notes in Geoinformation and Cartography, pages 119-155. Springer International Publishing, 2014.

[50] Guillaume Touya and Matthieu Baley. Level of details harmonization operations in OpenStreetMap based large scale maps. In Michael Leitner and Jamal Jokar Arsanjani, editors, Citizen Empowered Mapping, volume 18 of Geotechnologies and the Environment, pages 3-25. Springer International Publishing, 2017.

[51] Thomas C. van Dijk and Jan-Henrik Haunert. Interactive focus maps using least-squares optimization. International Journal of Geographical Information Science, pages 1-24, March 2014.

[52] Maxim A. Rylov and Andreas W. Reimer. A comprehensive multi-criteria model for high cartographic quality Point-Feature label placement. Cartographica, 49(1):52-68, 2014.

[53] Hugo Loi, Thomas Hurtut, Romain Vergne, and Joëlle Thollot. Discrete texture design using a programmable approach. In ACM SIGGRAPH 2013 Talks, SIGGRAPH '13, New York, NY, USA, July 2013. ACM.

[54] Hugo Loi, Thomas Hurtut, Romain Vergne, and Joelle Thollot. Programmable 2d arrangements for element texture design. ACM Trans. Graph., 36(3):27:1-27:17, May 2017.

[55] Sabine Hennig, Fritz Zobl, and Wolfgang W. Wasserburger. Accessible web maps for visually impaired users: Recommendations and example solutions. Cartographic Perspectives, 88, 2017.

[56] Nicolas Mellado, David Vanderhaeghe, Charlotte Hoarau, Sidonie Christophe, Mathieu Brédif, and Loic Barthe. Constrained palette-space exploration. ACM Transactions on Graphics, 36(4), July 2017.

[57] Sidonie Christophe. Cartographic styles between traditional and original (towards a cartographic style model). In AutoCarto Conference, September 2012.

[58] Sidonie Christophe, Bertrand Dumenieu, Jérémie Turbet, Charlotte Hoarau, Nicolas Mellado, Jérémie Ory, Hugo Loi, Antoine Masse, B. Arbelot, R. Vergne, Mathieu Brédif, Thomas Hurtut, Joëlle Thollot, and David Vanderhaeghe. Map style formalization: Rendering techniques extension for cartography. In David Mould and Pierre Bénard, editors, Proceedings of Non-Photorealistic Animation and Rendering, Lisbon, Portugal, May 2016.

[59] Guillaume Touya. Social welfare to assess the global legibility of a generalized map. In Ningchuan Xiao, Mei-Po Kwan, Michael F. Goodchild, and Shashi Shekhar, editors, Geographic Information Science 7th International Conference, GIScience 2012, volume 7478 of Lecture Notes in Computer Science, chapter 15, pages 198-211. Springer Berlin / Heidelberg, Berlin, Heidelberg, 2012.

[60] William A. Mackaness and A. Ruas. Evaluation in the map generalisation process. In William A. MacKaness, Anne Ruas, and L. Tiina Sarjakoski, editors, Generalisation of Geographic Information, pages 89-111. Elsevier, London, 2007. 
[61] Robert E. Roth, Arzu Çöltekin, Luciene Delazari, Homero F. Filho, Amy Griffin, Andreas Hall, Jari Korpi, Ismini Lokka, André Mendonça, Kristien Ooms, and Corné P. J. M. van Elzakker. User studies in cartography: opportunities for empirical research on interactive maps and visualizations. International Journal of Cartography, 3(sup1):61-89, October 2017. 